\title{
PENGARUH KEPEMIMPINAN TERHADAP KELELAHAN PERAWAT RAWAT INAP DI RUMAH SAKIT SOSIAL BOGOR, JAWA BARAT
}

\author{
${ }^{1}$ Sri Rahayu, ${ }^{2}$ Wahyu Sulistiadi, ${ }^{3}$ Hafiizhoh Fithriyyah, ${ }^{4}$ Nanny Harmani \\ 1Program Pascasarjana Ilmu Kesehatan Masyarakat Universitas Muhammadiyah Prof \\ Dr Hamka \\ ${ }^{2}$ Fakultas Kesehatan Masyarakat Universitas Indonesia \\ 3Program Pascacasarjana Ilmu Keperawatan Universitas Indonesia \\ ${ }^{4}$ Fakultas Ilmu Kesehatan, Universitas Muhammadiyah Prof Dr Hamka \\ wahyufphui@gmail.com
}

\begin{abstract}
ABSTRAK
Rumah Sakit Sosial (Rumah Sakit X) di yang berada di Bogor ini merupakan salah satu rumah sakit not for profit yang melayani pasien tidak mampu dengan rata-rata kondisi penyakit khronis dan terminal. Hal ini dapat menyebabkan kelelahan yang dapat terjadi pada perawat dengan jumlah sumber daya yang terbatas. Kondisi demikian membutuhkan kepemimpinan transformasional yang dapat mengelola sehingga tercipta layanan kesehatan dengan optimal. Desain penelitian ini kuantitatif analitik menggunakan data survey cross sectional study pada tahun 2014 tetapi masih dapat digunakan untuk menguji hipotesis dengan jumlah populasi perawat rawat inap 56 orang. Hasil penelitian ini signifikan ada pengaruh negative kepemimpinan transformasional terhadap kelelahan perawat rawat inap dengan nilai sig hitung 0,004 nilai $\mathrm{t}$ hitung -3,043 dengan konstanta B -0,657 artinya bila kepemimpinan transformasional diimplementasikan akan dapat menurunkan tingkat kelelahan perawat. Saran untuk para pimpinan rumah sakit selalu memperhatikan kondisi kelelahan yang terjadi pada perawat dan dapat mengganggu layanan keperawatan.
\end{abstract}

Kata kunci ; kelelahan, kepemimpinan transformasional, perawat, layanan keperawatan

\begin{abstract}
The Social Hospital (Hospital X) in Bogor is one of the not for profit hospitals that serves poor patients with an average chronic and terminal disease conditions. This can cause fatigue that can occur in nurses with limited amounts of resources. This condition requires transformational leadership who can manage to create optimal health services. This research design is quantitative analytic using cross sectional study survey data in 2014 but can still be used to test the hypothesis with a population of 56 inpatient nurses. The results of this study are significant, there is a negative effect of transformational leadership on the fatigue of inpatient nurses with a sig value of 0.004 with a value of t count -3.043 with a constant B -0.657 , meaning that if transformational leadership is implemented it will reduce the fatigue level of nurses. Suggestions for hospital leaders always pay attention to the fatigue conditions that occur in nurses and can interfere with nursing services.
\end{abstract}

Keywords ; fatigue, transformational leadership, nursing, nursing services

Korespondensi: wahyufphui@gmail.com 


\section{PENDAHULUAN}

Pengelolaan rumah sakit tidak akan terlepas dari sumber daya manusia yang ada dalam organisasi rumah sakit. Manajemen sumber daya manusia pada hakekatnya merupakan bagian integral dari keseluruhan manajemen institusi dan sumber daya manusia merupakan modal serta kekayaan yang terpenting dari seluruh kegiatan yang dilaksanakan. Rumah sakit merupakan sebuah industri layanan jasa kesehatan juga sebaiknya dikelola oleh Sumber Daya Manusia yang kompeten di bidang atau profesinya masing-masing baik di unit layanan medis, keperawatan, penunjang medis ataupun layanan umum (Tjiptono, 2006). Pada sistem layanan kesehatan di rumah sakit, perawat merupakan ujung tombak baik tidaknya layanan kesehatan yang diberikan kepada pasien karena selama 24 jam perawat selalu berinteraksi dengan pasien (Umar, 2003). Layanan yang baik tidak terlepas dari adanya komitmen dari perawat untuk memberikan layanan yang baik kepada pasien. Perawat adalah salah satu jenis tenaga kesehatan yang dikelompokkan dalam tenaga keperawatan. Tenaga keperawatan terdiri dari perawat dan bidan (Peraturan Pemerintah RI No.36/2014 pasal 11 tentang tenaga kesehatan). Oleh karena itu unit keperawatan di sebuah rumah sakit sangat penting dalam menentukan mutu atau kualitas layanan untuk meningkatkan proses penyembuhan pasien.

Perawat dianggap sebagai sosok yang sudah menyelesaikan suatu program pendidikan keperawatan, memenuhi syarat dan diberi wewenang oleh manajemen untuk memberikan layanan kesehatan yang bermutu klinis tinggi dan penuh tanggung jawab. Sehubungan dengan hal diatas, maka ketika menjalankan tugasnya mereka berhadapan dengan sumber stress yang melekat dengan bidang kerjanya. Selaku individu yang terlatih, ia akan melakukan proses pengkajian atas sumber stress dan melakukan pemilihan strategi yang tepat untuk mengatasi stress. Perawat selaku pekerja kesehatan ada pada kelompok layanan umum, dimana mereka harus memberikan layanan yang optimal agar tercapai kesembuhan pasien. Namun disisi lain, mereka sehari-hari menghadapi sejumlah masalah seperti keselamatan dirinya, kemungkinan penularan penyakit/infeksi nosokomial, beban kerja yang tinggi, ketidak nyamanan fisik, terjebak dalam konflik antara keinginan untuk memenuhi kebutuhan pasien dan keluarganya, serta perasaan tidak berdaya sampai penyebab sakitnya pasien ditemukan (Shane, Steven and Ann, 2005).

Bertambahnya beban kerja seseorang serta keadaan fisik yang kurang mendukung, perawat saat bekerja dapat merasakan kelelahan. Banyak penelitian menunjukan bahwa faktor individu dalam hal ini antara lain umur, masa kerja, status perkawinan dan gizi mempunyai pengaruh menimbulkan kelelahan (Eraliesa, 2009). Kelelahan kerja dapat menimbulkan masalah bagi organisasi atau perusahaan karena simpton kelelahan kerja dapat muncul dalam bentuk komitmen kerja menurun, frustasi, penurunan semangat kerja, turnover, hilangnya dedikasi dan kreativitas individu. Hasil penelitian diantara profesi di bidang kesehatan, perawat memiliki tingkat stress yang lebih tinggi dibanding dokter dan apoteker. Tingginya stress yang harus dihadapi perawat rentan terhadap munculnya gejala-gejala burnout (Eviaty and Satiadarma, 2005).

Di Indonesia terdapat tiga jenis rumah sakit dengan fungsi yang berbeda; pertama adalah rumah sakit pemerintah yang mengemban fungsi politis dan sosial, kedua adalah rumah sakit swasta yang berfungsi sosial serta ketiga adalah rumah sakit swasta yang berfungsi sebagai berorientasi laba. Ketiga jenis rumah sakit tersebut kini berkembang mendapat porsi perhatian yang seimbang di masyarakat. Rumah Sakit dalam penelitian ini adalah rumah sakit swasta yang berfungsi social (not for profit) dimulai pada tahun 2001 oleh sebuah yayasan sosial dengan awalnya mendirikan Balai Pengobatan yang memberikan akses layanan kesehatan yang layak dan optimal secara tidak berbayar bagi masyarakat tidak mampu secara ekonomi. Layanan Balai Pengobatan ini memberikan layanan kesehatan tingkat dasar. Dalam perkembangannya Balai 
Pengobatan ini harus melayani pasien-pasien tidak mampu yang membutuhkan pelayanan spesialistik, rawat inap dan juga tindakan operatif yang berdampak fasilitas layanan yang ada menjadi tidak memadai lagi. Atas dasar itulah yayasan sosial tersebut mendirikan layanan kesehatan tingkat rujukan yang akan memberikan layanan kesehatan tingkat rujukan sekelas rumah sakit pada tahun 2012.

Tabel 1. Jumlah Pasien Rawat Inap Rumah Sakit X Januari s/d Juni 2014

\begin{tabular}{lcccccc}
\hline \multicolumn{1}{c}{ Rawat Inap } & Januari & Februari & Maret & April & May & Juni \\
\hline Rawat Pria & 40 & 29 & 44 & 41 & 46 & 50 \\
\hline Rawat Wanita & 32 & 35 & 39 & 36 & 45 & 68 \\
\hline Rawat Anak & 16 & 25 & 24 & 24 & 26 & 37 \\
\hline Rawat Kebidanan & 14 & 21 & 21 & 25 & 13 & 21 \\
\hline HCU & 10 & 12 & 17 & 14 & 8 & 7 \\
\hline Total & $\mathbf{1 1 2}$ & $\mathbf{1 2 2}$ & $\mathbf{1 4 5}$ & $\mathbf{1 4 0}$ & $\mathbf{1 3 8}$ & $\mathbf{1 8 3}$ \\
\hline
\end{tabular}

Sumber ; Data Kinerja Rekam Medis Rumah Sakit X Tahun 2014

Tabel 2. Sepuluh Besar Penyakit di Rawat Inap Januari s/d Maret 2014

\begin{tabular}{|c|c|c|c|}
\hline No & Januari & Februari & Maret \\
\hline 1 & Congestive Heart Failure & TB Paru & TB Paru \\
\hline 2 & Chronik Kidney Disease & Congestive Heart Failure & Congestive Heart Failure \\
\hline 3 & TB Paru & Stroke & $\begin{array}{l}\text { Dengue Haemorrhagic } \\
\text { Fever }\end{array}$ \\
\hline 4 & Diabetes Mellitus & GEA & Anemia \\
\hline 5 & Pneumonia & Diabetes Mellitus & Chronik Kidney Disease \\
\hline 6 & Dyspepsia & Dyspepsia & Pneumonia \\
\hline 7 & Hipertensi & Pneumonia & Diabetes Mellitus \\
\hline 8 & Anemia & Anemia & Stroke \\
\hline 9 & $\begin{array}{l}\text { Dengue Haemorrhagic } \\
\text { Fever }\end{array}$ & $\begin{array}{l}\text { Dengue Haemorrhagic } \\
\text { Fever }\end{array}$ & Dyspepsia \\
\hline 10 & CA Mammae & Chronik Kidney Disease & GEA \\
\hline
\end{tabular}

Sumber ; Data Rekam Medis Tahun 2014

Tabel 3. Sepuluh Besar Penyakit di Rawat Inap April s/d Juni 2014

\begin{tabular}{clll}
\hline No & \multicolumn{1}{c}{ April } & \multicolumn{1}{c}{ Mei } & Juni \\
\hline 1 & Congestive Heart Failure & TB Paru & CKD \\
\hline 2 & TB Paru & Bronchopneumonia & TB Paru \\
\hline 3 & Anemia & Chronik Kidney Disease & Congestive Heart Failure \\
\hline 4 & Diabetes Mellitus & Anemia & GEA \\
\hline 5 & Chronik Kidney Disease & CHF & $\begin{array}{l}\text { Dengue Haemorrhagic } \\
\text { Fever }\end{array}$ \\
\hline 6 & Dengue Haemorrhagic & Dengue Haemorrhagic & Bronchopneumonia \\
\hline 7 & Pever & Fever & Diabetes Mellitus \\
\hline 8 & Dyspepsia & Diabetes Mellitus & Pneumonia \\
\hline 9 & GEA & Thalassemia & Atrial Fibrilation \\
\hline 10 & Stroke & ISK & CA Mammae \\
\hline
\end{tabular}


Jumlah pasien rawat inap di Rumah Sakit X mengalami kenaikan hampir setiap bulannya dengan jenis penyakit yang bervariasi dan beberapa kasus terminal diserta dengan jumlah perawat yang terbatas bisa menyebabkan terjadi kelelahan pada diri perawat rawat inap Individu yang mengalami kelelahan kerja merasa tidak dihargai oleh organisasi atau rekan kerjanya yang berakibat individu tersebut menjadi tidak perhatian terhadap kebutuhan organisasi karena banyak sekali berbuat kesalahan dan tidak adanya pencapaian target kerja.

Akibat negatif dari kelelahan adalah kemungkinan timbul emosi perawat yang tidak sesuai yang diharapkan pasien dan secara tidak langsung berpengaruh terhadap produktifitas produktifitas perawat. Aspek psikologis emosi mengganggu kondisi mental dan lebih menekankan pada hubungan interpersonal antara perawat dengan kepala ruang, perawat dengan perawat lainnya dan hubungan perawat dengan pasien, yang dapat mempengaruhi keserasian dan produktifitas kerja bagi perawat sebagai alokasi penggunaan waktu guna peningkatan layanan keperawatan terhadap pasien.

Organisasi yang berhasil dalam mencapai tujuan serta mampu memenuhi tanggug jawab sosialnya akan sangat tergantung pada para manajernya (pimpinan). Bila pimpinan mampu melaksanakan dengan baik, sangat mungkin organisasi tersebut akan mencapai sasarannya. Suatu organisasi membutuhkan pemimpin yang efektif, yang mempunyai kemampuan mempengaruhi perilaku anggotanya atau anak buah. Jadi, seorang pemimpin atau kepala suatu organisasi akan diakui sebagai seorang pemimpin apabila ia dapat mempunyai pengaruh dan mampu mengarahkan bawahannya kearah pencapaian tujuan organisasi. Kualitas dari pemimpin seringkali dianggap sebagai faktor terpenting dari keberhasilan atau kegagalan organisasi (Menon, 2002) demikian juga keberhasilan atau kegagalan suatu organisasi baik yang berorientasi bisnis maupun publik (sosial), biasanya dipersepsikan sebagai keberhasilan atau kegagalan pemimpin.

(Bilha and Halamish, 2008) mengemukakan bahwa di antara tiga gaya kepemimpinan yang hirarkis terstruktur dari Bass dan Avolio, pemimpin yang optimal adalah orang yang menunjukkan sebagian besar gaya transformasional, sedangkan gaya transaksional dan gaya pasif-menghindari (avoiding styles) pada tingkat yang lebih rendah. Pada era persaingan global, banyak organisasi menggeser paradigma gaya kepemimpinan mereka dari kepemimpinan transaksional ke kepemimpinan transformasional sebagai cara untuk mencapai strategi dan tujuan. Gaya kepemimpinan transformasional sesuai dengan lingkungan organisasi yang dinamis (Ismail et al., 2011). Kepemimpinan transformasional dianggap efektif dalam situasi atau budaya apa pun (Yukl, 2010).

Berdasarkan jumlah pasien rawat inap yang setiap bulannya meningkat terus dan 10 besar penyakit di Rumah Sakit X yang merupakan penyakit kronis dengan tingkatan terminal diagnosis, hal ini membutuhkan pengelolaan layanan asuhan keperawatan yang optimal. Dalam pengelolaan sumber daya manusia khususnya keperawatan untuk menghadapi kondisi kerja yang melelahkan dan cukup tinggi resikonya, satu hal penting bagi kelangsungan kemampuan kerja yang tinggi dari para karyawan adalah kemampuan peran kepemimpinan organisasi didalam meletakkan dasar-dasar pembinaan dan penentuan arah sasaran organisasi. Tanpa peran kepemimpinan yang baik dan paham terhadap pola tugas dan sasaran organisasi akan sulit diharapkan layanan keperawatan yang optimal. Atas dasar inilah peneliti akan melakukan penelitian dan menganalisa data hasil penelitian adanya pengaruh kepemimpinan transformasional terhadap kelelahan perawat pelaksana rawat inap di Rumah Sakit X sebagai rumah sakit sosial (not for profit) dalam wilayah Bogor. 


\section{METODE}

Desain penelitian ini kuantitatif analitik dengan tehnik pengumpulan data cross sectional study dengan total sampling semua perawat pelaksana rawat inap dengan jumlah 56 perawat. Survey penelitian ini dilakukan pada tahun 2014 tetapi data hasil penelitian dianalisa tahun 2020 dengan asumsi masih dapat digunakan untuk uji hipotesis dan kondisi karakteristik pasien dan kekhususan sebagai rumah sakit sosial satu-satunya di Parung Bogor masih sama hingga sekarang. Variabel kelelahan para perawat pelaksana dinilai oleh kepala ruang masing-masing ruang rawat inap sedangkan variable kepemimpinan transformasional para pimpinan langsung perawat pelaksana dinilai oleh para perawat pelaksana rawat inap. Hasil ukur masing-masing variabel menggunakan skala likert.

\section{HASIL}

Karakteristik perawat di rawat Inap di rumah sakit ini relative mempunyai variasi yang tidak terlalu lebar. Dari 4 karakteristik, komposisi gender lelaki dan perempuan tidak jauh berbeda.

Tabel 4. Distribusi Karakteristik Perawat Rawat Inap

\begin{tabular}{|c|c|c|c|c|}
\hline No & \multicolumn{2}{|c|}{ Faktor } & $\mathbf{n}$ & $\%$ \\
\hline \multirow{2}{*}{1} & \multirow{2}{*}{ Status pernikahan } & Belum kawin & 47 & 83,9 \\
\hline & & Kawin & 9 & 16,1 \\
\hline \multirow{2}{*}{2} & \multirow{2}{*}{ Jenis kelamin } & Laki-laki & 24 & 42,9 \\
\hline & & Perempuan & 32 & 57,1 \\
\hline \multirow{2}{*}{3} & \multirow{2}{*}{ Pendidikan } & D3 & 53 & 94,6 \\
\hline & & NERS & 3 & 5,4 \\
\hline \multirow{4}{*}{4} & \multirow{4}{*}{ Usia } & $20-25$ tahun & 42 & 75 \\
\hline & & $26-30$ tahun & 11 & 19.64 \\
\hline & & 31 - 35 tahun & 2 & 3.57 \\
\hline & & $36-40$ tahun & 1 & 1.79 \\
\hline
\end{tabular}

Tabel 4 menunjukkan karakteristik perawat pelaksana rawat inap dengan jumlah yang belum kawin $83,9 \%$, perempuan $57,1 \%$ dan hamapir semuanya lulus pendidikan tinggi terampil D3, selain itu pada umumnya masih berusia produktif muda (75\%) dan belum menikah.

Tabel 5. Distribusi Variabel Kelelahan

\begin{tabular}{cllcc}
\hline No & & Indikator & $\mathbf{n}$ & $\mathbf{\%}$ \\
\hline \multirow{2}{*}{1} & \multirow{2}{*}{ Emotional exhaustion } & Emosi stabil & 22 & 39,29 \\
& & Kelelahan emosi & 34 & $\mathbf{6 0 , 7 1}$ \\
\hline \multirow{2}{*}{2} & \multirow{2}{*}{ Activities } & $\begin{array}{l}\text { Tidak ada penurunan } \\
\text { aktivitas fisik }\end{array}$ & 29 & 51,79 \\
& & Ada penurunan aktivitas fisik & 27 & 48,21 \\
\hline \multirow{2}{*}{3} & \multirow{2}{*}{ Mistakes } & Tidak melakukan kesalahan & 22 & 39,29 \\
& & Melakukan kesalahan & $\mathbf{3 4}$ & $\mathbf{6 0 , 7 1}$ \\
\hline
\end{tabular}

Sumber data primer tahun 2014.

Tabel 5 menampilkan bahwa tingkat kelelahan para perawat pelaksana di Rumah Sakit X cukup tinggi yaitu; indikator kelelahan emosi $60,71 \%$, ada penurunan aktivitas fisik 48,21\% dan melakukan kesalahan dalam layanan keperawatan 60,71\%. 
Tabel 6. Distribusi Variabel Kepemimpinan

\begin{tabular}{|c|c|c|c|c|}
\hline No & & Indikator & $\mathbf{n}$ & $\%$ \\
\hline \multirow{2}{*}{1} & \multirow{2}{*}{ Idealized Influenced } & Kurang memberikan pengaruh & 41 & 73,20 \\
\hline & & Cukup baik & 15 & 26,80 \\
\hline \multirow{2}{*}{2} & \multirow{2}{*}{$\begin{array}{l}\text { Inspirational } \\
\text { Motivation }\end{array}$} & Kurang memberikan inspirasi & 40 & 71,40 \\
\hline & & Cukup memberikan inspirasi & 16 & 28,60 \\
\hline \multirow{2}{*}{3} & \multirow{2}{*}{ Intelectual Stimulation } & Kurang meningkatkan intelektual & 48 & 85,70 \\
\hline & & Dapat meningkatkan intelektual & 8 & 14,30 \\
\hline \multirow[b]{2}{*}{4} & \multirow{2}{*}{$\begin{array}{l}\text { Individualized } \\
\text { Consideration }\end{array}$} & Kurang memberikan pertimbangan & 40 & 71,43 \\
\hline & & $\begin{array}{l}\text { Cukup bijak dalam memberikan } \\
\text { pertimbangan }\end{array}$ & 16 & 28,57 \\
\hline
\end{tabular}

Sumber data primer tahun 2014

Implementasi kepemimpinan transformasional belum terlaksana dengan baik, hal ini ditunjukkan pada tabel 6 yaitu; pada indikator pemimpin kurang memberikan pengaruh 73,20\%, kurang memberikan inspirasi 71,40\%, kurang meningkatkan tingkat intelektual 85,70\% dan kurang memberikan pertimbangan $71,43 \%$.

Untuk kelayakan model dilakukan ujin anova berikut ini

Tabel 7. Anova ${ }^{a}$

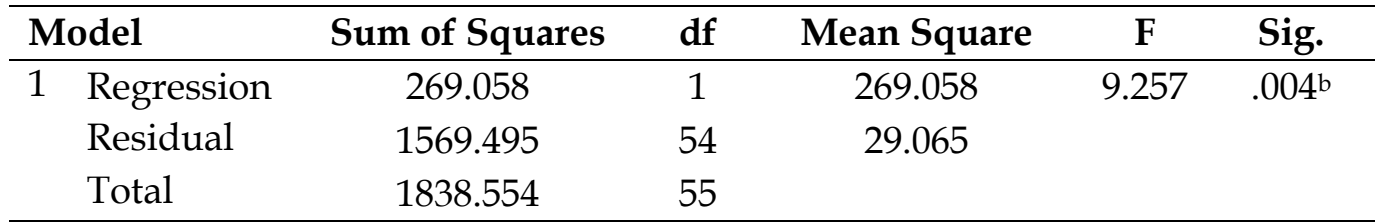

a. Dependent Variable: Kelelahan

b. Predictors: (Constant), Kepemimpinan

Nilai sig hitung pada tabel $7=0,004<a(0,05)$ dan nilai F hitung $=9,257>$ F tabel $(4,01)$ yang berarti model ini layak sebagai model regressi.

Tabel 8.

Koefisien Regresi Pengaruh Kepemimpinan Transformasional Terhadap Kelelahan

\begin{tabular}{|c|c|c|c|c|c|c|c|c|}
\hline \multirow{2}{*}{\multicolumn{2}{|c|}{ Model }} & \multicolumn{2}{|c|}{ Unstandardized Coefficients } & \multirow{2}{*}{$\begin{array}{c}\text { Standardized Coefficients } \\
\text { Beta }\end{array}$} & \multirow{2}{*}{$\mathbf{t}$} & \multirow{2}{*}{ Sig. } & \multicolumn{2}{|c|}{$95.0 \%$ Confidence Interval for $B$} \\
\hline & & B & Std. Error & & & & Lower Bound & Upper Bound \\
\hline \multirow{2}{*}{1} & (Constant) & 63.140 & 10.044 & & 6.287 & .000 & 43.004 & 83.276 \\
\hline & Kepemimpinan & -.657 & .216 & -.383 & -3.043 & .004 & -1.090 & -.224 \\
\hline
\end{tabular}

Nilai sig hitung pada tabel 8 yaitu $0,004<a(0,05)$ dan nilai $\mathrm{t}$ hitung $=-3,043>\mathrm{t}$ tabel $(1,67303)$ yang berarti terima $\mathrm{H} 1$ artinya signifikan ada pengaruh kepemimpinan transformasional negative terhadap kelelahan perawat pelaksana rawat inap di Rumah Sakit X. Persamaan regressi yang dihasilkan adalah:

$\mathrm{Y}=63,140+(-0,657) \mathrm{X}+$ Std Error

Makna persamaan ini adalah bila dilaksanakan atau diimplemantasikan kepemimpinan transformasional di Rumah Sakit $X$ khususnya pimpinan langsung perawat pelaksana rawat inap maka akan menurunkan tingkat kelelahan perawat sebesar 0,657.

Tabel 9. Model Summary

\begin{tabular}{llrrr}
\hline Model & R & \multicolumn{1}{c}{ R Square } & Adjusted R Square & Std. Error of the Estimate \\
\hline 1 & $.383^{\mathrm{a}}$ & .146 & .131 & 5.39117 \\
\hline
\end{tabular}


Berdasarkan tabel 9 diketahui bahwa besarnya pengaruh negative kepemimpinan transformasional terhadap kelelahan perawat adalah $14,6 \%$ dan sisanya sebesar 85,4\% dipengaruhi oleh variabel lainnya.

\section{DISKUSI}

Karakteristik perawat pelaksana rawat inap di Rumah Sakit $\mathrm{X}$ dengan jumlah terbesar pada usia produktif yaitu 20 - 25 tahun dan dengan proporsi terbesar belum menikah/kawin hal ini merupakan keuntungan dari segi kesiapan fisik dalam melakukan layanan keperawatan dengan tuntutan jumlah pasien rawat inap yang selalu meningkat jumlahnya dengan kondisi diagnose penyakit khronis. Akan tetapi bukan hanya kesiapan fisik saja yang dibutuhkan tetapi kesiapan mental pun dibutuhkan dalam melakukan layanan keperawatan. Sehingga dari hasil penelitian didapat tingkat kelelahan cukup tinggi pada masing-masing indkator kelelahan yaitu; indikator kelelahan emosi $60,71 \%$, ada penurunan aktivitas fisik 48,21\% dan melakukan kesalahan dalam layanan keperawatan 60,71\%. Kelelahan kerja yang ditandai oleh adanya perasaan lelah, output menurun, dan kondisi fisiologis yang dihasilkan dari aktivitas terusmenerus merupakan suatu kelompok gejala yang berhubungan dengan adanya penurunan efisiensi kerja, keterampilan serta peningkatan kecemasan atau kebosanan. Kondisi kerja dapat memprediksi adanya kelelahan emosional tetapi bila perawat melakukan layanan keperawatan dengan memiliki sifat kepribadian conscientiousness, penuh kehati-hatian dalam bekerja dan mengikuti alur serta standar prosedur operasional akan menghasilkan stabilitas emosional yang berdampak menurunkan kelelahan emosional(Chen et al., 2020).

Layanan keperawatan saat ini semakin kompleks dan dihadapkan dengan berbagai tantangan, antara lain peningkatan beban kerja baik layanan asuhan keperawatan klinis dan administrasi keperawatan yang menyebabkan meningkatnya kelelahan dan peningkatan biaya kesehatan, sebagai salah satu profesi dengan jumlah terbesar, perawat sering menjadi sorotan, sehingga pemimpin keperawatan harus terus memperbaiki pendekatan dan gaya kepemimpinan agar lebih efektif. Pemimpin dalam keperawatan diharapkan dapat menggerakkan sistem dari satu titik ke titik lainnya dalam upaya pemecahan masalah. Maka secara konstan pemimpin harus mengembangkan strategi untuk merubah orang lain dan memecahkan permasalahan yang terjadi pada organisasi yang dipimpinnya (Puspitasari and Dwiantoro, 2017).

Kepemimpinan transformasional adalah suatu kepemimpinan di mana pemimpin memotivasi bawahannya untuk mengerjakan lebih dari yang diharapkan semula dengan meningkatkan rasa pentingnya bawahan dan nilai pentingnya pekerjaan. Perawat yang pada saat bekerja mendapatkan perlakuan baik dari pemimpinnya, meskipun beban kerja dan tuntutan kerja tinggi maka kemungkinan terjadinya kelelahan yang menyebabkan burnout akan rendah karena saat dia bekerja, dia merasakan bahwa apa yang dilakukannya adalah sebuah prestasi, dan seseorang akan merasa senang jika memiliki prestasi, perasaan senang inilah yang mencegah terjadinya burnout (Sanches, Souza and Lima, 2018).

Upaya menurunkan kelelahan perawat pelaksana dalam bekerja melakukan layanan keperawatan diantaranya dengan melaksanakan kepemimpinan transformasional walaupun besarnya pengaruh hanya $14,6 \%$ antara lain;

a. Pengaruh Ideal (Idealized Influenced) yaitu dengan memberi contoh positive kepada perawat pelaksana sebagai mitra kerja dalam perilaku, memberikan perhatian kepada bawahan yaitu dengan menanyakan kondisi personal dan masalah dalam lingkungan kerja, membuat dan sosialisasi visi untuk menanamkan rasa bangga pada unit kerjanya sendiri yang berdampak bangga pada organisasi.

b. Motivasi Inspirasional (Inspirational Motivation) yaitu pimpinan mampu menstimulasi antusiasme dalam bekerja, mengembangkan keyakinan untuk mencapai tujuan bersama, dan 
membangkitkan semangat bekerja dalam upaya proses penyembuhan pasien. Untuk meningkatkan motivasi diantaranya pimpinan memberikan penghargaan bagi yang berprestasi dan hukuman bagi yang melanggar peraturan.

c. Stimulasi Intelektual (Intelectual Stimulation) yaitu pimpinan menciptakan iklim kondusif bagi pengembangan ide, melibatkan bawahan dalam merumuskan masalah dan mencari solusi serta memfasilitasi pelatihan. Memberikan pengarahan dan petunjuk yang jelas sehingga semua informasi atau pengetahuan yang disampaikan dapat dimengerti/dipahami serta dapat diimplementasikan dengan optimal.

d. Perhatian individual (Individualized Consideration) yaitu pimpinan memberikan perhatian secara personal, menjalin kerjasama yang baik dengan perawat pelaksana dan menghargai setiap perbedaan individu serta dapat mengarahkan semua potensi perawat di lingkungan kerjanya untuk mencapai tujuan organisasi sehingga mampu membangkitkan kepuasan kerja karyawan yang dapat berdampak menurunkan kelelahan.

Selain dari pimpinan, perawat juga diharapkan dapat melaksanakan arahan yang diberikan oleh pimpinan dan melaksanakan tanggung jawab yang diberikan dengan sebaik-baiknya.

\section{SIMPULAN}

Berdasarkan hasil penelitian ini dapat disimpulkan bahwa kepemimpinan transformasional berpengaruh negative untuk menurunkan kelelahan perawat pelaksana rawat inap di Rumah Sakit X sebagai Rumah Sakit Sosial di Bogor, Jawa Barat. Empat dimensi kepemimpinan transformasional yaitu pengaruh ideal (idealized influence), motivasi inspirasional (inspirational motivation), stimulasi intelektual (intellectual stimulation) dan perhatian individual (individualized consideration) mampu mengurangi atau menurunkan kelelahan selama melakukan layanan keperawatan kepada pasien. Masih beruntung rumah sakit ini memiliki perawat yang muda sehingga factor kelelahan bisa tertutupi, akan tetapi dalam jangka waku lama maka kemungkinan kelelahan tidak teratasi dan akan terjadi peningkatan turn over perawat.

Untuk mengoptimalkan layanan keperawatan yang tidak menimbulkan kelelahan perawat rawat inap, hendaknya kepemimpinan transformasional perlu diterapkan pada level manajemen di bagian layanan kesehatan terutama bidang keperawatan sehingga perawat terhindar dari kelelahan akibat beban pekerjaan yang cukup dan layanan kesehatan lebih optimal.

\section{UCAPAN TERIMA KASIH}

Terima kasih diucapkan kepada Direktur RS X sebagai Rumah Sakit Sosial di Bogor. Penelitian ini didukung oleh Program Pascasarjana Ilmu Kesehatan Masyarakat Universitas Muhammadiyah Prof DR Hamka dan Pusat Pendidikan Pelayanan Masyarakat, Fakultas Kesehatan Masyarakat Universitas Indonesia.

\section{DAFTAR PUSTAKA}

Bilha, M. and Halamish, H. (2008) 'Transformational leadership as related to team outcomes', Development Journal, Vol 29, No 7, pp. 617-630., Vol 29(Leadership), pp. 617-630. Available at:

https://www.emerald.com/insight/content/doi/10.1108/01437730810906353/full/html.

Cavazotte, F., Moreno, V. and Hickmann, M. (2012) 'Effects of leader intelligence, personality and emotional intelligence on transformational leadership and managerial performance.', The Leadership Quarterly, 23(3), 443-455., Vol 23(Leadership), pp. 443-455. Available at: https://psycnet.apa.org/record/2012-11599-010. 
Chen, H. et al. (2020) 'Work engagement, emotional exhaustion, and counterproductive work behavior', Journal of Business Research 114 (2020) 30-41, Vol 114(Emotional exhaustion), pp. 30-41. doi: https// doi.org//1016/j.jbusres.2020.03.025.

Eraliesa, F. (2009) Hubungan Faktor Individu Dengan Kelelahan Kerja Pada Tenaga Kerja Bongkar Muat Di Pelabuhan Tapaktuan Kecamatan Tapaktuan Kabupaten Aceh Selatan. Universitas Sumatera Utara.

Eviaty and Satiadarma, M. . (2005) 'Persepsi Terhadap Dukungan Rekan Sekerja dan Gejala Burnout (Studi pada Perawat Unit Perawatan Intensif)', Jurnal Phronesis, Jakarta Fakultas Psikologi Tarumanegara., Vol $7 \quad$ No.2(Psikologi). Available at: http://repository.untar.ac.id/10092/1/IMG_0085.jpg.

Ismail, A. et al. (2011) 'An Empirical Study of the Relationship between Transformational Leadership, Empowerment and Organizational Commitment', Journal, Vol 2, No 1, pp. 89107., Vol 2(Transformational Leadership), pp. 89-107. Available at: http://www.ajindex.com/dosyalar/makale/acarindex-1423873787.pdf.

Maslach, C. and Jackson, S. E. (1981) 'The measurement of experienced burnout $\dagger^{\prime}$ ', Journal of Occupational Behavior, Vol II, h.99-113., Vol II(Burnout), pp. 99-113. Available at: https://onlinelibrary.wiley.com/doi/abs/10.1002/job.4030020205.

Menon, M. E. (2002) 'Perceptions of pre-service and in-service teachers regarding the effectiveness of elementary school leadership in Cyprus', International Journal of Educational Management 16(2):91-97 · April 2002, Vol 16, pp. 91-97. Available at: https://www.researchgate.net/publication/235273952_Perceptions_of_preservice_and_in-

service_teachers_regarding_the_effectiveness_of_elementary_school_leadership_in_Cypr us.

Puspitasari, N. W. and Dwiantoro, L. (2017) 'Transformational Leadership dalam Menurunkan Beban Kerja Perawat Puskesmas', Jurnal Ilmiah Ilmu Keperawatan Indonesia, Vol. 7 No.(Workload), pp. 346-354.

Robbins, S. P. and Judge, T. . (2008) Perilaku Organisasi. Edisi kedu. Jakarta: Jakarta: Salemba Empat.

Sanches, R. S., Souza, A. R. de and Lima, R. S. (2018) 'Factors related to the development of stress and burnout among nursing professionals who work in the care of people living with HIV/aids', INTEGRATIVE REVIEW OF THE LITERATURE, 10(1):276-, pp. 276-282. doi: DOI: 10.9789/2175-5361.2018.v10i1.276-282.

Setiawati, D. (2010) Determinan Kinerja Perawat Di Ruang Rawat Inap Rumah Sakit AL Dr. Mintohardjo Jakarta Tahun 2010. Universitas Indonesia.

Shane, M., Steven, L. and Ann, G. V. M. (2005) Organizational Behaviour. Boston: Mc Graw Hill.

Tjiptono, F. (2006) Strategi Bisnis dan Manajemen. Yogyakarta: Andi Offset, Yogyakarta.

Umar, H. (2003) Evaluasi Kinerja Perusahaan. Gramedia Pustaka Utama, Jakarta. Jakarta: Gramedia Pustaka Utama, Jakarta.

Yukl, G. (2010) Kepemimpinan Dalam Organisasi. Jakarta: Edisi Indonesia. Jakarta: Penerbit PT Indeks. 